\title{
Imagens das escolas: sobre redes de conhecimentos e currículos escolares
}

\author{
Nilda Alves*
}

\section{RESUMO}

$\mathrm{O}$ artigo trata do espaçotempo escolar, entendendo-o como dimensão material do currículo. Busca, a partir de imagens criadas pelo artista/fotógrafo francês Robert Doisneau, mostrar que o espaçotempo escolar é composto de relações múltiplas entre múltiplos sujeitos com saberes múltiplos, que aprendem/ensinam, o tempo todo, múltiplos conteúdos de múltiplas maneiras.

Palavras-chave: espaçotempo escolar, redes de conhecimentos, cotidiano escolar.

\begin{abstract}
This paper deals with school in time and space, and it presents it as a material dimension of a curriculum. School in time and space is made up of multiple relations among multiple subjects who are multiply wise and who teach and learn about multiple contents in many ways all the time starting from images created by the French artist and photographer Robert Doisneau.
\end{abstract}

Key-words: schools in time and space, knowledge network, daily routines in schools.

* Professora titular - Universidade Estadual do Rio de Janeiro. nildaalves@uol.com.br 


\section{Imagens da aula: sobre espaçostempos ${ }^{1}$ de aprenderensinar $^{2}$}

Por muito tempo, em uma sociedade que foi formada em torno do sentido da visão e da perspectiva, não se teve clareza da importância da imagem para a compreensão e o conhecimento da realidade, em especial, porque isso exigiria, junto à crítica da mesma, a indicação da possibilidade de superação da própria lógica dominante, que tinha aquele sentido e aquele parâmetro como definidor da realidade e da veracidade. Essa posição começa, hoje, a ser invertida, e estamos colocando sob suspeita o que poderíamos chamar "o império da imagem". É preciso reconhecer, no entanto, que este movimento se dá sob esse mesmo "império" crescente, ainda, quanto ao espaçotempo que ocupa em nossas vidas. Com isso, é quase impossível falar de algo sem usar imagens - sejam literárias, sejam visuais. Mais do que isso, a própria crítica só pode existir na medida em que dominemos, pelo uso e pelas teorias, todo esse vasto campo.

Pronta para dialogar com essa tendência dominante colocando-me no campo da crítica, decidi assumir a possibilidade/necessidade de falar da escola e mais exatamente do espaçotempo escolar, entendendo-o como dimensão material do currículo (ALVES, 1998) e assumindo sua multiplicidade e complexidade.

Parto, assim, da idéia de que se a "escola", singularizada e concretizada em um edifício, é uma criação da burguesia ascendente (séculos XIV, XV, XVI e XVII), são incontáveis espaçostempos nos quais se aprendeensina, em múltiplas redes cotidianas nas quais conhecimentos são criados e trocados (ALVES, 1999). Isso, de certa maneira, é proclamado, hoje, como uma grande "invenção" atual pela burguesia "anti-estatista", com pompa e circunstância: "é possível aprender por toda parte e de muitas maneiras!" No entanto, hoje, esta afirmativa tem o perigoso sentido de permitir uma possível negação da "escola pública, universal e laica", que tão pouco interessa, no presente, aos que desejam criar a "nova ordem econômica e social". Muito antes, porém dessa afirmativa "oficial", aprendemosensinamos nos múltiplos cotidianos em que vivemos (SANTOS, 1995) e, entre eles, o da escola, no qual

1 Para mostrar a única possibilidade de existência desses termos - um tem relação com o outro e só existe nesta relação - os juntei em uma única palavra.

2 O mesmo vale para esses termos. Neles no entanto, além de juntá-los em um só, inverti a ordem com que são ditos. 
não conseguimos "ver" que este é um espaçotempo de relações múltiplas entre múltiplos sujeitos com saberes múltiplos, que aprendem/ensinam, o tempo todo, múltiplos conteúdos de múltiplas maneiras.

Busco mostrar isso, neste texto, usando imagens criadas por um artista/ fotógrafo francês de quem gosto muito: Robert Doisneau.

Quero lembrar, no entanto, desde já que ao usar imagens, escolhidas/ selecionadas por mim, estou mostrando "uma" escola: aquela que o artista quis mostrar, naquele espaçotempo. Dependendo do interesse de quem mostra e de quem criou a imagem, em um determinado momento histórico, vale a pena mostrar a correção, a igualdade reinante, a disciplina, a calma, a colaboração, a professora tranqüila ou cheia de autoridade. Em outros, a tristeza, a desordem, o castigo, as escaramuças ou as disputas. Precisamos entender, assim, que em uma obra vão aparecer tanto as emoções que o artista desejou transmitir como a sintonia que ele tem, mesmo que disso não se dê conta, com um determinado momento da história, aquele no qual vive. Mas nela existe também os tantos sentidos daquele que, com sua história, suas emoções e suas memórias, vê a imagem.

Assim, é preciso ter presente que se as imagens têm um significado para mim, podem mostrar outras coisas para quem as vai 'ver', ao ler este trabalho. Isso porque, como nos lembra SAMAIN (1996), citando GOMBRICH, ${ }^{3}$ "a significação de uma imagem permanece em grande parte tributária da experiência e do saber que a pessoa que a contempla adquiriu anteriormente. Neste tocante, a imagem visual não é uma simples representação da 'realidade’ e sim um sistema simbólico" (p. 11). Dessa maneira, toda a análise que fizer estará, necessariamente, dentro das redes de significação de minhas experiências, mas precisará contar com a possibilidade de estabelecer relações, formar redes, com os significados que aquele/aquela que a for ler, neste texto, tiver sobre os espaçostempos da escola e da sala de aula. De um certo modo, isso me é garantido, já que esse, se é leitor/leitora, deve ter ido à escola e freqüentado salas de aula.

Por fim, preciso observar, ainda, que o uso de imagens no que se refere ao estudo do cotidiano, pode ajudar no trabalho teórico-epistemológico no/ sobre/do mesmo, já que estamos, segundo MAFFESOLI (1996), em um momento em que é necessário discutir e criar a ética da estética. Esse autor nos traz um exemplo para possibilitar a compreensão dessa expressão:

3 Cf. GOMBRICH, E. L' Écologie das images. Paris: Flammarion, 1983. 
$\mathrm{Na}$ Viena 'fin de siècle', uma cultura plástica, sensual, amante da natureza opunha-se ao espírito burguês, laborioso, moralista, que tinha por única ambição dominar a natureza e explorá-la. O burguesismo é essencialmente distintivo, tem por valor último o indivíduo e suas particularidades. Por outro lado, a cultura alternativa é uma cultura de grupo, é, como diz Schorske ${ }^{4}$, uma “Gefühlkultur" (cultura dos sentimentos); perfeitamente amoral, repousa sobre o prazer e o desejo de estar junto, sem objetivo particular e sem objetivo específico. [...] Será que Viena 'fin de siècle', que viu essas duas culturas se defrontarem, não foi, de certa forma, um exemplo premonitório? É verdade que a moral burguesa foi triunfante, mas é possível que a cultura dos sentimentos, um tempo desfeito, tenha continuado a importunar a civilização e, por meio de algumas vanguardas, não tenha deixado de se difundir de múltiplas maneiras. [...] Sabe-se, é sempre com discrição, às vezes até secretamente, que se difundem as mudanças de importância, até que um dia tornam-se evidências que é difícil negar, mesmo se não são compreendidas, nem aprovadas. [...] É essa sinergia, ainda bem misteriosa, bem pouco teórica, que, com muita certeza, serve de terreno às diversas agregações afetivas, que, aliás, designei pela metáfora de 'neotribalismo' (p. 56).

Por isso tudo, senti necessidade de usar a imagem, como espaçotempo, para a discussão sobre o cotidiano da escola e os múltiplos currículos que aí são criados e estão em permanente disputa.

E mais ainda: entendo, que neste momento de tantas dificuldades e de descrições tão sombrias sobre seu cotidiano, as escolas e seus sujeitos precisam ser vistos em sua potência histórica e sua beleza, que só a arte sabe nos apresentar.

\section{Mas o diabo do tambor!...}

No seu Conto de escola, cujas últimas palavras trouxe para o título desta parte, Machado de Assis nos narra como um aluno aprende em um só dia, com colegas seus, a corrupção e a delação. Mas muitas e complexas outras coisas também se aprende na escola, entre elas valores positivos como a solidariedade. Um dos grandes "problemas" da "escola", singularizada e apropriada pela

4 SCHORSKE, C. E. Vienne fin de siècle - politique et culture. Paris: Seuil, 1983. 
burguesia, criada estimulando a competição em situações nas quais "vencem os mais fortes" e eliminando os que não sabem ou os que incomodam porque são diferentes, é a cola. Esse processo inerente a esse tipo de escola, que é o dominante em nossa sociedade, é considerado, assim, um absurdo inaceitável e por isso mesmo perseguido, e os alunos que nessa situação se 'deixam pegar' são, em geral, punidos. Há professores/professoras que, assumindo significados mais complexos sobre isso, tentam discutir as situações que geram tantas dificuldades para os alunos/alunas, como as de avaliação, e assumem que a cola é um momento importante de aprendizagemensino. ${ }^{5}$

\section{Sobre "cola" e solidariedade}

Da grande coleção de fotografias sobre a escola feita por Doisneau, vou buscar quatro para discutir alguns dos tipos de aprendizagemensino que vivemos no cotidiano escolar, inclusive, e principalmente, a tessitura da solidariedade entre alunos, através de momentos de cola. Eis a primeira:

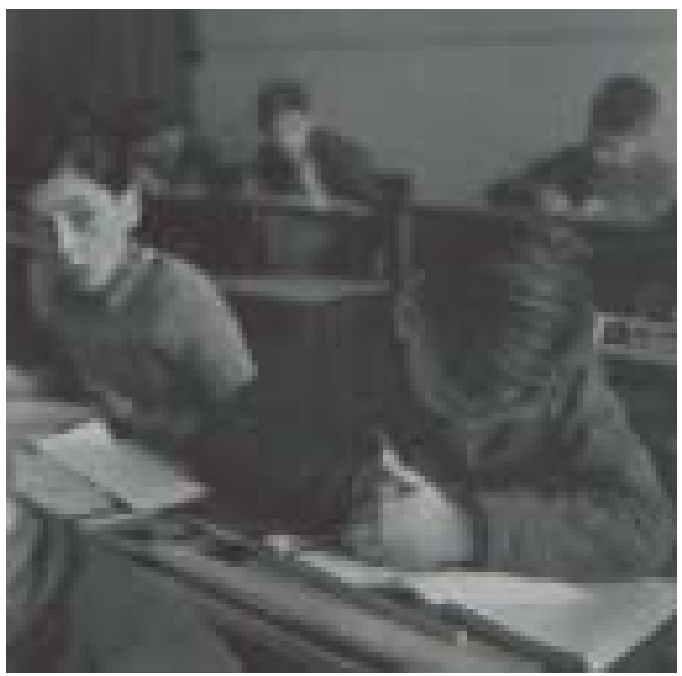

5 O profissional que mais criativamente atacou esse problema, entre os que conheço, é Dirceu Castilho Pacheco, meu colega de Faculdade, que agora prepara sua dissertação de Mestrado sobre o tema, sob a minha orientação. 
Não adianta o colega implorar, tentar subornar, prometer mundos e fundos... o aluno que, com todo o seu corpo cobre o "exercício" - e quantos significados esta palavra pode ter - já aprendeu que não pode ajudar o outro. Como aprendeu? O que significa ter aprendido isso? Em seu corpo retorcido, na cabeça baixa, nas duas mãos que cobrem o que escreve - que posição mais difícil! - este aluno mostra que aprendeu a "lição". O olhar do colega ao lado que interroga - sobre o que? - não o "toca" ou talvez o faça esconder ainda mais aquilo que "já aprendeu" ser sua propriedade: a resposta que sabe sobre o que a professora ensinou e perguntou. Essa situação, no entanto, é bem diferente daquela que é mostrada na imagem seguinte, talvez a mais famosa fotografia de Doisneau, na qual um "distraído", não está "nem aî" para o que o colega que está a seu lado está fazendo:

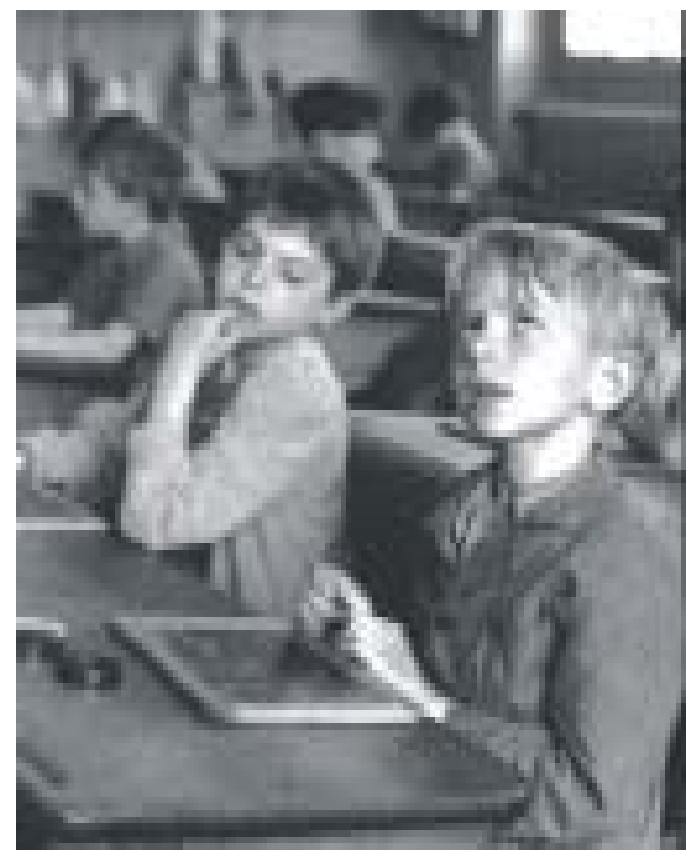

Minhas redes de significação, tecidas em meus múltiplos contextos cotidianos e no caso em questão com minhas experiências no cotidiano da escola, permitem-me dizer que se estes meninos se sentam juntos, talvez sejam amigos e brinquem um com o outro. O que pensa é reconhecido pelo outro, na situação fotografada, como sabendo a lição. Entende, por isso, que a lousa 
sobre a qual seu colega escreveu já tantas coisas deve conter a "revelação" do problema (contas?) que a professora "passou". Este último, que parece tanto saber e que em seus pensamentos está tão absorto, não tem nenhuma preocupação de esconder seu trabalho. Quem sabe, sempre fazem trabalho juntos e gostam muito? Se a professora "não criar caso", a ação se completa: o que olhou, entendeu o que havia, aprendeu, e vai escrever também na sua lousa. Talvez seja necessária ainda uma pequena pergunta e uma breve resposta esclarecedora, quem sabe? Nessas trocas, conhecimentos são passados, criados, reproduzidos, sem que ninguém perceba, algumas vezes, e com trágicas conseqüências, outras vezes, como aconteceu no conto de Machado a que fiz referência. Há momentos, ainda, em que as ações de ambos são bem mais explícitas. Eis um exemplo:

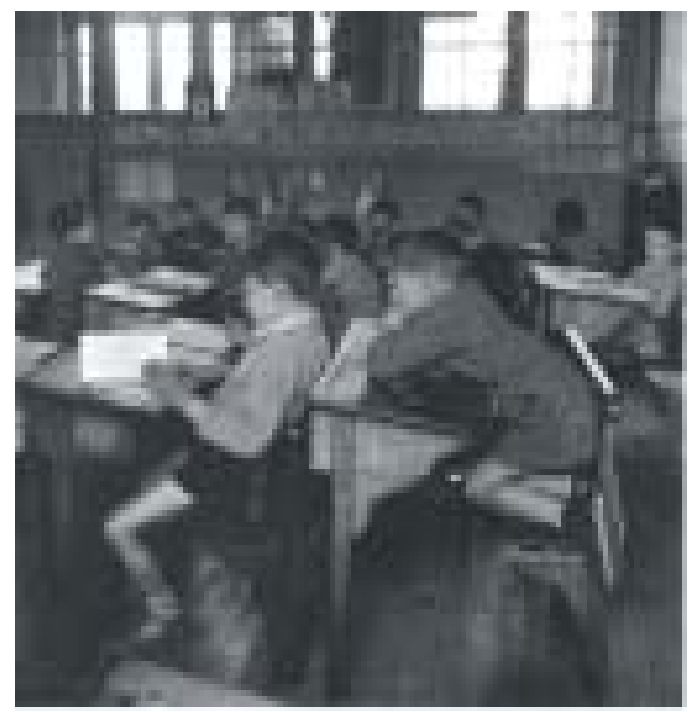

Pela tranqüilidade que reina na sala, nada nos faz crer que o momento é o de tensão de uma prova. Mas a imagem pode me servir para mostrar o que seria uma terceira etapa do aprendizagemensino da colaboração e da solidariedade. O aluno que está sentado atrás se ajoelhou para melhor poder olhar alguma coisa que o colega, sentado à sua frente, lhe quer mostrar. Este, para facilitar a visão do outro, escorregou o corpo para a frente. E se fosse uma resposta de prova? A maioria de nós já viveu situação semelhante: como aluno e como professor/ professora. Como reagimos nessas situações? Que conse- 
qüências presenciamos em situações parecidas? Por fim, vejamos uma situação em que o "jogo" é mais claro e a solidariedade mais ativa no que se refere ao colega que "dá a cola":

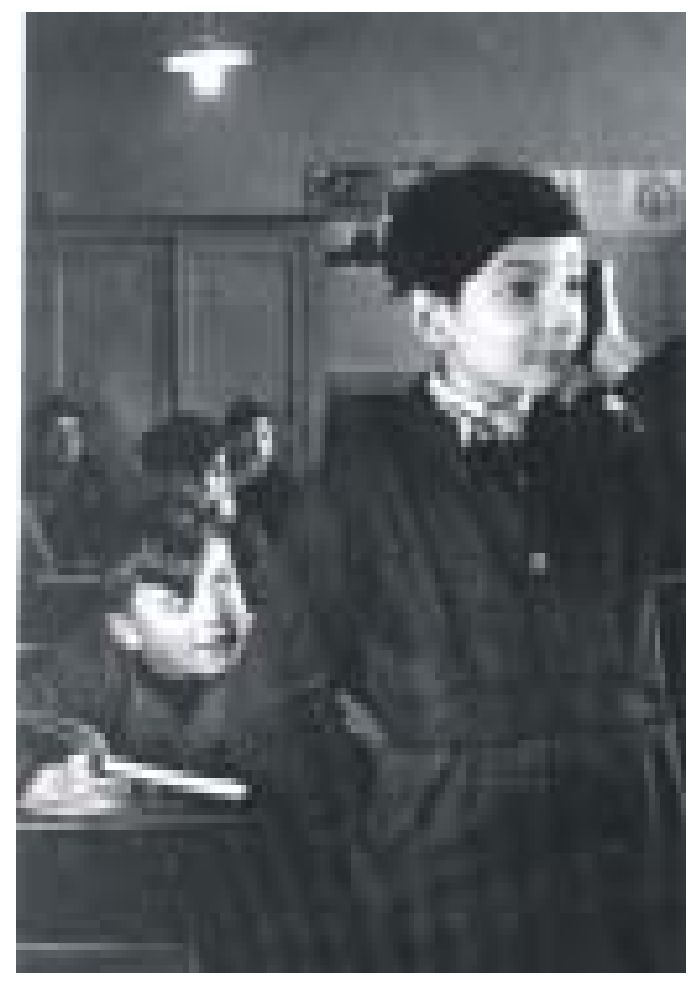

Aqui sim, a situação é mesmo de tensão! O olhar ansioso dos três alunos no fundo da sala e as mãos sobre a boca de um deles nos mostram a aflição que percorre o ambiente. Um aluno de pé tem que responder a uma questão formulada pela professora. O mexer na orelha, às vezes o coçar a cabeça, mostra que ele não sabe a resposta. Um colega seu, sentado na carteira seguinte, que já aprendeu que para isso precisa se esconder atrás do corpo do que está em pé, abriu o livro ou o caderno, procurou rapidamente a resposta e a está "soprando" para o colega, escondendo a boca, mas sem medo aparente das consequiências. Seu rosto é, sem dúvida, o mais tranqüilo da fotografia. Por quê? Por que a professora não fica zangada e até mesmo estimula essas ações? Por que, apesar das possíveis conseqüências, é mais importante ajudar 
o amigo nas horas de dificuldades? Por que se sabe que é para dizer ao colega que, em momento de grande aflição, precisa dar a resposta em voz alta?

Quatro imagens de um mesmo artista que mostram as inúmeras redes de conhecimentos que vão, a cada instante, sendo organizadas em um fluir que não foi previamente planejado, mas que marcam, de forma indelével, os que nelas vivem e as organizam.

Aquele olhar de lado que se repete, ainda hoje e sempre, se uma situação de prova se apresenta, continua levando a posições de corpos muito parecidas às vistas nas imagens mostradas. Vale a pena prestar atenção, observar, estudar, analisar e compreender situações iguais a estas para entender melhor nossas redes cotidianas de aprenderensinar e as maneiras como são tecidos os currículos no dia-a-dia das escolas e das salas de aula.

Além disso, o bom ou mau sucesso desse olhar tem sequiência nos resultados das avaliações realizadas através de provas e exames e que, sempre, são tornados públicos. Muitas vezes, são expostos em quadros e paredes sem comentários e sem se preocupar em como os alunos/as alunas que os recebem se sentem. No entanto, no momento de olhar esses resultados, para se garantir de surpresas, cada um se faz acompanhar, com freqüência, por um colega que, solidariamente, vai trazer seu apoio no caso de insucesso ou vai vibrar junto em caso de sucesso.

Sucesso ou insucesso proclamado, depois de um apoio particular, todos, porque são jovens e "tribais" (MAFFESOLI, 1998), se reúnem à saída da escola, dentro ou fora dela, para comemorar... a vida!

\section{REFERÊNCIAS}

ALVES, N. Tecer conhecimento em rede. In: ALVES, N.; GARCIA, R. L. $O$ sentido da escola. Rio de Janeiro: D, P \& A, 1999. p. 111- 120.

. O espaço escolar e suas marcas - o espaço escolar como dimensão material do currículo. Rio de Janeiro: D, P \& A, 1998.

MAFFESOLI, M. No fundo das aparências. Petrópolis: Vozes, 1996.

O tempo das tribos - o declínio do individualismo nas sociedades de massa. Rio de Janeiro: Forense, 1998.

SAMAIN, E. Questões heurísticas em torno do uso das imagens nas ciências 
sociais. In: BARROS, A. M. (Org). Anais do Seminário 'Pedagogia da imagem, imagem da Pedagogia’. Niterói: UFF/ Faculdade de Educação, 1996. p. 07-17.

SANTOS, B. S. Pela mão de Alice - o social e o político na pós-modernidade. São Paulo: Cortez, 1995. 